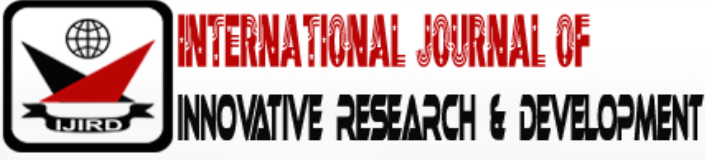

ISSN 2278-0211 (Online)

\section{Modeling of Rectangular Reinforced Concrete Columns Strengthened Externally Using CFRP Sheets by Finite Element Analysis}

\author{
Dr. Ali Hussein Mohamed Ali \\ Assistant Professor, Department of Civil Engineering, College of Engineering \& Architecture, \\ University of Bahri, Sudan \\ Thanoon Mahmood Ali Mohammed \\ M.Sc. Student, Department of Civil Engineering, College of Engineering \& Architecture, \\ University of Bahri, Sudan
}

\section{Abstract}

The behavior of $R C$ concrete columns of rectangular shape wrapped with "CFRP" has not been studied extensively, so a $R C$ concrete column with dimensions of $150 \times 300 \times 500 \mathrm{~mm}$ has been modeled and a nonlinear analysis was made using the finite element method (FEM). Three dimensional eight-node brick element (SOLID65) was used to represent the concrete; three-dimensional Spar (3D) element (LINK180) represented the steel and using a three-dimensional shell element (SHELL81) to represent the "CFRP" composites and epoxy resin. The experimental data were used taking into account the axial capacity and orientation of the fibers.

In this study, the results of the ANSYS program (Release 2020 R2 ACADIMIC) were compared with the practical and theoretical data, as the results showed a significant improvement in the ductility and axial capacity of" CFRP" strengthened columns compared to the unstrengthened columns. Ones when strengthened the columns by one layer the axial load capacity was increased $4.2 \%$, three layers 30\%, Moreover 77\% when strengthened by five layers.

Keywords: Carbon Fiber Reinforced Polymer, Rectangular Columns, Confined concrete, Non-linear

\section{Introduction}

Fiber Reinforced Polymers (FRP) are materials composed of fibers combined with a polymeric matrix. They appear as an alternative in relation to conventional materials for strengthening and rehabilitation of structures. FRP is lightweight, non-corrosive and has high tensile strength. In fabric format, the FRP can be used to wrap the structure to promote strengthening. Fibers and resins are expensive if compared to traditional materials; however, they allow strengthening of the structure in a relatively short time and demand a lower degree of structure intervention. In addition to this, it is possible to apply them in places with difficult access (ACI 440.2R-08). In recent years, FRP composites are used as externally bonded reinforcement to concrete structures for essentially two purposes: to provide confinement to concrete subjected to compression (jacketing system), and to improve bending and/or shear strength of a reinforced concrete flexural member such as beam, slab, etc. The confinement pressure provided by the FRP increases continuously with the lateral strain of concrete because of the linear elastic stress-strain behavior of FRP, in contrast to steel confined concrete in which the confining pressure remains constant when the steel is in plastic flow. Failure of FRP-wrapped concrete generally occurs when the hoop rupture strength of the FRP is reached (Hajsadeghi, Alaee, Shahmohammadi, 2010)

The cost of rebuilding the concrete structure compared to its repair and reinforcement is very high. For this reason, we must understand modern technologies and study them in a way that enables us to choose the best decisions, to save money and time. A 3D model of a rectangular concrete column reinforced with CFRP layers was developed externally using ANSYS software and compared the theoretical solution using experimental equations with the practical solution and the ANSYS solution. In addition, studies of the change of some parameters such as the effect of CFRP thickness, and the direction of roll angle with respect to CFRP layers. In some previous studies, the bonding between reinforced concrete and 
CFRP layers is assumed ideal, while in the current study the epoxy resin layers that were simulated with Shall 181 represented this bonding, where the lower layers adhering to the concrete column body were given the properties of the Epoxy resin and the rest of the layers properties The CFRP. Do the results of analyzing the rectangular concrete column in this way give us close and logical results if compared with the laboratory and theoretical results, and what is the effect of the thickness of the concrete column and the orientation of the fire on the strength and elasticity of the column?

\section{Literature Review}

In confinement, using CFRP notably reduced concrete cover spelling and delayed concrete core crushing. This study dealt with the assessment of compressive behaviour of 18 short, square and low- strength concrete columns confined with both externally bonded CFRP and conventional transverse reinforcement. The studied parameters were steel ratio $(2.8 \%$ and $5.6 \%)$ and configuration of transverse steel reinforcement, as well as carbon fiber volumetric ratio $(0.3 \%$ and $0.5 \%$ ). Test results also showed that the mean value in concrete peak strength for the columns with greater volumetric carbon fibre ratio $(0.5 \%)$ was $17 \%$ higher than those of columns with the smaller volumetric carbon fiber ratio $(0.3 \%)$, and 79\% higher than those of columns without carbon fiber reinforcement (Carrilloa \&Valencia-Minab \& Bojórquez, 2019). The distribution of compressive stresses in the cross section of the column indicated that for centered load, circular cross sections had uniform distribution and for square and rectangular sections, parabolas and concentrates next to the rounded corners defended the effective confined concrete. For eccentric load, the effective confined region moves to the most confined edge, thus, this did not reduce the gain for Square and rectangular columns, but is unfavourable for circular columns (OLIVEIRA \& CARRAZEDO, 2019). Loading capacity and strains of square reinforced concrete (RC) columns, strengthened with external carbon fibre reinforced polymer (CFRP) sheets, were tested and evaluated. Results clearly demonstrate that composite wrapping can enhance the structural performance of RC columns in terms of both maximum strength and ductility. The effects of test parameters are evidenced and compared (A. Benredjem1 \& N. Chikh, 2018).

\section{Finite Element molding of Strengthened RC Columns.}

In this study a finite element model for rectangular RC column confined with FRP composites is developed. The model is simulated using ANSYS (Release 2020R2 Academic) finite element software Solid 65, Solid 186, Link 180 and Shell 181, elements are used to represent concrete, loading steel plates, main steel and stirrups reinforcing bars and carbon fiber (CFRP) composites with epoxy resin respectively. The geometry, node locations, and the coordinate system for ANSYS elements are shown in Figure (1)

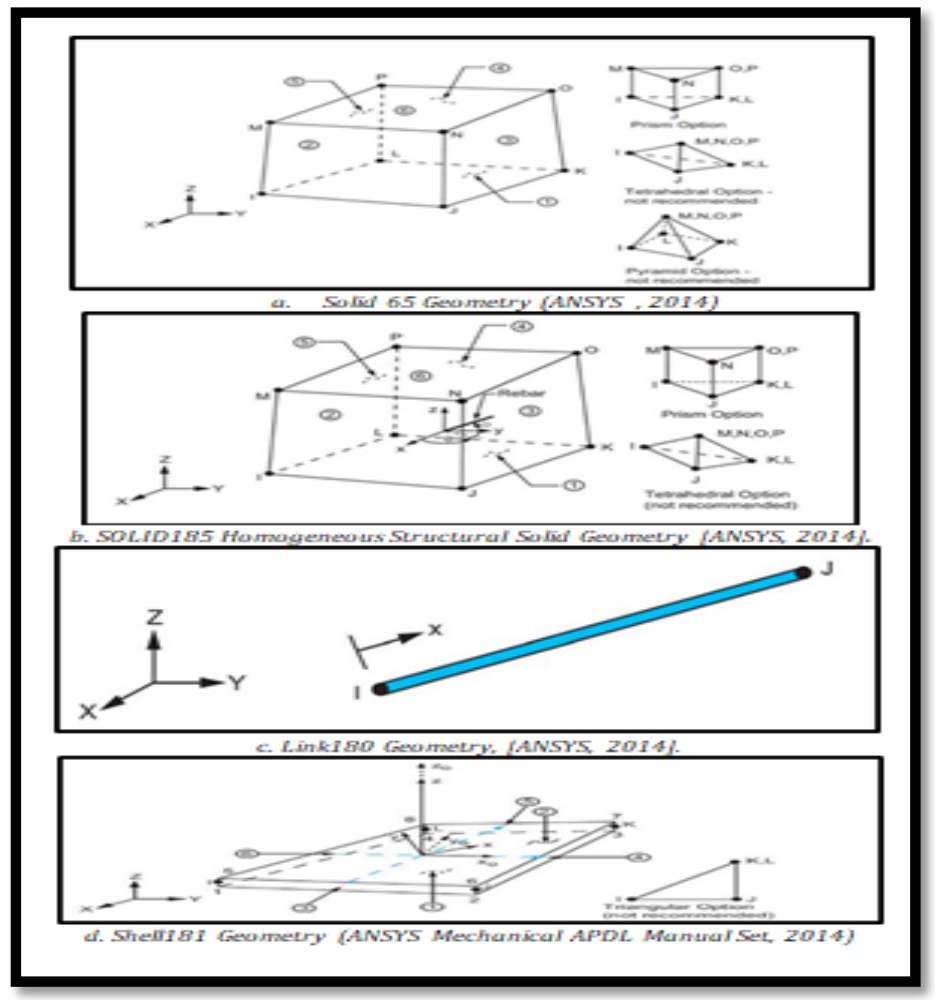

Figure 1: Geometry Elements ANSYS 


\subsection{Material Properties}

Finite element models for CFRP wrap columns are presented. First, the material properties are identified, then are inserted in program software in this study, the ANSYS is used for modeling of concrete column, reinforcement, epoxy resin, and CFRP sheet. The nonlinear analysis is developed by means of ANSYS/STANDARD to simulate the nonlinear behavior of the confined column. After that the geometry of model is defined, and material properties should be introduced. First, elastic behavior of material is set. Hence, the elastic parameters such as: Young's modulus of concrete, $E_{c}$ and Poisson's ratio, $v$ are inputted. From experimental results $E_{c}$ is calculated as $E_{c}=4700 \sqrt{f_{c}^{\prime}}$ (ACI 8.5.1), where is given in MPa. The popular stress-strain relationship is used to make the uniaxial compressive simulation of the concrete column, which is given by the following relationships (Desayi, Prakash, and Krishnan 1964).

$$
\begin{aligned}
& f_{r}=0.62 \sqrt{f_{c}^{\prime}} \\
& \varepsilon_{o}=\frac{2 f_{c}}{E_{c}} \\
& f=\frac{E_{c} \varepsilon}{1+\left(\frac{\varepsilon}{\varepsilon_{o}}\right)^{2}}
\end{aligned}
$$

Where:

$f_{c}=$ stress at any strain

$\varepsilon_{0}=$ strain at the ultimate compressive strength $f^{\prime}{ }_{c}$

$\varepsilon=$ strain at stress $f_{c}$

$f^{\prime}{ }_{c}=$ ultimate compressive strength

$f_{r}=$ uniaxial tensile strength

In this study, the cylindrical compressive strength of using concrete was 26.4 MPa and Poisson's ratio ( $v_{c}$ ) of concrete was assumed to be 0.2 The shear transfer coefficient represents a shear strength reduction factor for subsequent loads that induce sliding (shear) across the crack face, [Chansawat et al., 2009]. Typical shear transfer coefficients range from 0.0 to 1.0, with 0.0 representing a smooth crack (complete loss of shear transfer) and 1.0 representing a rough crack (no loss of shear transfer), [ANSYS 2014]. For an open crack, the shear transfer coefficient varied between 0.05 and 0.50 in many studies of reinforced concrete structures, [Isenburg, 1993]. In this study, many analysis attempts had been done to determine the appropriate values of shear transfer coefficients based on comparison of FE load-displacement values with experimental results. The open and closed cracks shear transfer coefficients used in this study for shear column models are 0.3 and 0.99 respectively the uniaxial cracking stress of concrete (tensile strength) is based upon the modulus of rupture. Modulus of rupture of concrete is a more variable property than the compressive strength from Eq. (1) (Mohammad H., 2015).

A value uniaxial crushing stress was taken (-1) for removes the crushing capability (Mechanical APDl Theory Reference.) Modified Hognestad mathematical model (See Figure (2)) has been used for the approximation of the stress-strain behavior of concrete. Equations (2) and (3) were used to predict the multilinear isotropic stress strain curve for the concrete. The multilinear curve was used to help with convergence of the nonlinear solution algorithm, [Wolanski, 2004]. Figures (3) shows the stress-strain relationship used in this study for ANSYS model respectively. The curve starts at zero stress and strain. Point 2, defined as $0.3 f^{\prime}{ }_{c}$, and was calculated in the linear range. Points from 3 to 20 were calculated from Eq. (3) with $\varepsilon_{o}$ obtained from Eq. (2). Strains were selected and the stress was calculated for each strain. Point 20 is at $f^{\prime}{ }_{c}$. After Point 19, perfectly plastic behavior of concrete was assumed. Software ANSYS requires input data for Material properties as shown in Table 1.

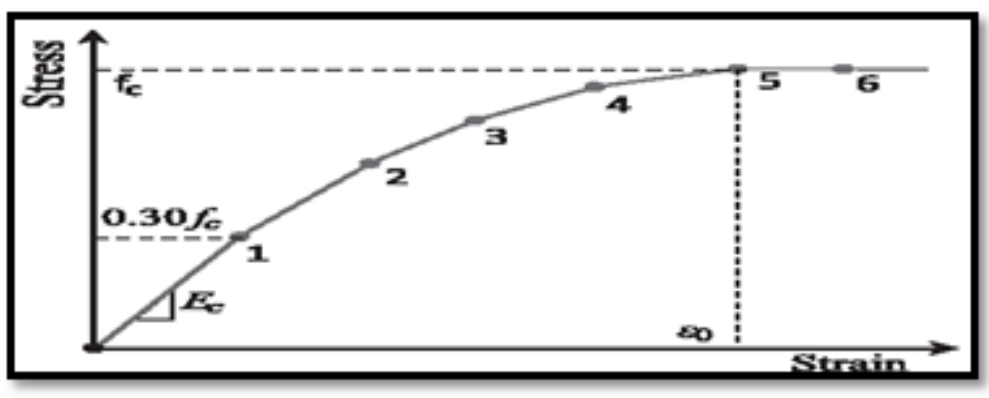

Figure 2: Uniaxial Stress-Strain Behavior of Concrete (Basappa \& and Rajagopal, 2013) 


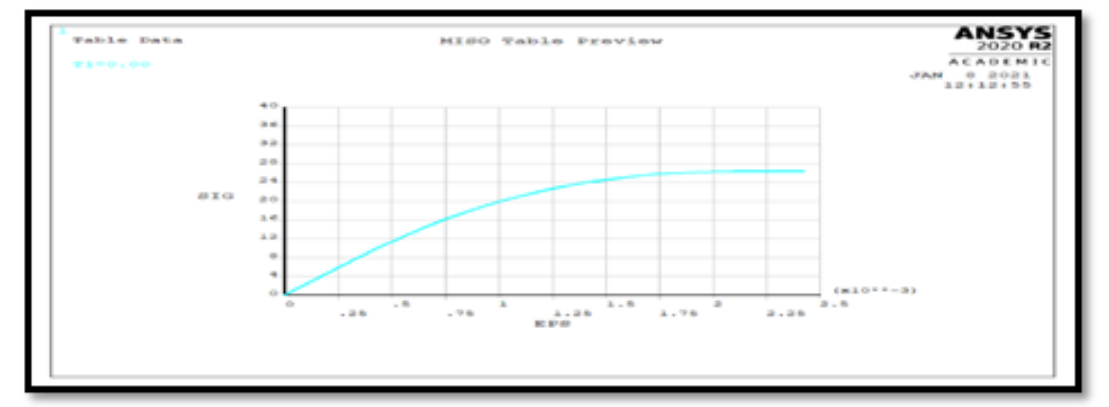

Figure 3: Compressive Uniaxial Stress-Strain Curve for Concrete ANSYS Model

In addition, material properties of steel reinforcement used for ANSYS column models, define material as a bilinear models recommended in several previous researches requires the Yield Stress $\left(f_{y}\right)$, as well as the Hardening Modulus (tangent modulus of the plastic region) of steel to be defined Elastic Modulus $\left(E_{x}\right)$, also defined Poisson's Ratio ( $\left.v_{x}\right)$. In this study, two types of steel reinforcing bars were used with diameters of $8 \mathrm{~mm}$ and $12 \mathrm{~mm}$. the yield stress $\left(f_{y}\right)$ and strain $\left(\varepsilon_{y}\right)$ of the bars with diameters of $8 \mathrm{~mm}$ and $12 \mathrm{~mm}$, were $476 \mathrm{Mpa}$ and 0.0024, 339 Mpa and 0.0017, respectively, Elastic Modulus $\left(E_{x}\right)$ was $200000 \mathrm{Mpa}$. The Poisson's ratio of the steel reinforcement $\left(v_{x}\right)$ was 0.3 , Table 2 shown properties FE model foe steel reinforcement. The bond between steel bars and concrete is considered perfect. Surely, as the CFRP behavior is orthotropic, the CFRP material is inputted as a linear elastic orthotropic material in the model. Without a doubt, it is necessary to introduce properties of the CFRP for every course independently; the mechanical properties of the CFRP that were used in this study are shown in Table 3. A local coordinate system for the CFRP shell element was defined where the $\mathrm{x}$ direction is the same as the fiber direction, while the $\mathrm{y}$ and $\mathrm{z}$ directions were perpendicular to the $\mathrm{x}$ direction. The elastic modulus in the fiber direction of the unidirectional CFRP material used in the experimental studies was specified by the manufacturer, major Poisson's ratio was assumed, and then, the elastic modulus in directions perpendicular to the fiber direction, minor Poisson' ratio, and shear modulus were predicted using Rule of Mixture.

$G_{x y}=\frac{E_{x} E_{y}}{E_{x}+E_{y}+2 v_{x y} E_{x}}$

Where:

$G_{x y}=$ Shear modulus in the xy plane

$E_{\mathrm{x}}=$ Elastic modulus in the $\mathrm{x}$ direction

$E_{y}=$ Elastic modulus in the y direction

$v_{x y}=$ Major Poisson's ratio

Equation (4) shows the relationship between elastic and shear moduli (ANSYS 1998). The bond between concrete and CFRP by epoxy resin which mechanical properties show in Table 4 is simulated as shell181 element. The base and loading plates were modelled with the mechanical properties of steel shown in Table 5. 


\begin{tabular}{|c|c|c|c|c|}
\hline \multirow{35}{*}{$\begin{array}{l}\text { Element Type } \\
\text { Solid } 65\end{array}$} & \multicolumn{4}{|c|}{ Material Properties } \\
\hline & \multicolumn{4}{|c|}{ Linear Isotropic } \\
\hline & \multirow{2}{*}{\multicolumn{2}{|c|}{$\begin{array}{l}E_{x} \\
P R_{x y}\end{array}$}} & \multirow{2}{*}{\multicolumn{2}{|c|}{$\begin{array}{l}23294.12(\mathrm{Mpa}) \\
0.2\end{array}$}} \\
\hline & & & & \\
\hline & \multicolumn{4}{|c|}{ Multi-linear Isotropic } \\
\hline & Point & & Strain & Stress (Mpa) \\
\hline & 1 & & 0 & 0 \\
\hline & & & 0.00034 & 7.92 \\
\hline & 3 & & 0.00044 & 10.16 \\
\hline & 4 & & 0.00054 & 12.23 \\
\hline & 5 & & 0.00064 & 14.16 \\
\hline & 6 & & 0.00074 & 15.96 \\
\hline & 7 & & 0.00084 & 17.6 \\
\hline & 8 & & 0.00094 & 19.08 \\
\hline & 9 & & 0.00104 & 20.4 \\
\hline & 10 & & 0.00114 & 21.57 \\
\hline & 11 & & 0.00124 & 22.58 \\
\hline & 12 & & 0.00134 & 23.46 \\
\hline & 13 & & 0.00144 & 24.19 \\
\hline & 14 & & 0.00154 & 24.8 \\
\hline & 15 & & 0.00164 & 25.3 \\
\hline & 16 & & 0.00174 & 25.8 \\
\hline & 17 & & 0.00184 & 25.98 \\
\hline & 18 & & 0.00194 & 26.19 \\
\hline & 19 & & 0.00204 & 26.32 \\
\hline & 20 & & 0.00214 & 26.39 \\
\hline & 21 & & 0.0022 & 26.4 \\
\hline & & Open shear & Coefficient transfer & 0.3 \\
\hline & & Closed shear & Transfer coefficient & 0.99 \\
\hline & & Uniaxial cracking & Stress & 3.18 \\
\hline & & Uniaxial crushing & Stress & -1 \\
\hline & & Biaxial crushing & Stress & default \\
\hline & & Hydrostatic & Pressure & default \\
\hline & & Hydro biaxial & Crushing stress & default \\
\hline & & Tensile crack & factor & default \\
\hline
\end{tabular}

Table 1: Material Properties of Concrete FE Model

\begin{tabular}{|l|c|l|}
\hline Element Type & Material Properties & \\
\hline Link 180 & Linear Isotropic & \\
\hline & $E_{x}$ & $200000 \mathrm{Mpa}$ \\
\hline For $\Phi 12 \mathrm{~mm}$ & $P R_{x y}$ & 0.3 \\
\hline & Bilinear isotropic & \\
\hline For $\Phi 8 \mathrm{~mm}$ & Yield stress & $339 \mathrm{Mpa}$ \\
& Tangent modulus & $339 \mathrm{Mpa}$ \\
& Cross-section & \\
& Area of link & $113 \mathrm{~mm}^{2}$ \\
& Bilinear isotropic & \\
& Yield stress & $476 \mathrm{Mpa}$ \\
& Tangent modulus & $476 \mathrm{Mpa}$ \\
& Cross-section & \\
& Area of link & $50.24 \mathrm{~mm}^{2}$ \\
\hline
\end{tabular}

Table 2: Material Properties Used for FE Model of Steel Reinforcement 


\begin{tabular}{|c|c|c|}
\hline Element Type & Description & Data \\
\hline Shell 181 & Tensile elasticity modulus & $=230 \mathrm{GPa},=3 \mathrm{GPa}$ \\
\hline & Shear elasticity modulus & $=2064 \mathrm{GPa}=1136 \mathrm{Gpa}$ \\
\hline & Poisson's ratio & $\mathrm{FALSE}$ \\
\hline & Tensile strength & $=3430 \mathrm{Mpa}$ \\
\hline & Ultimate rupture strain & 0.015 \\
\hline & Nominal thickness & $=0.165 \mathrm{~mm} / \mathrm{ply}$ \\
\hline
\end{tabular}

Table 3: Mechanical Properties of CFRP Sheets FE Model

\begin{tabular}{|c|c|c|}
\hline Element Type & Description & Data \\
\hline Shell 181 & Tensile elasticity modulus & $=3 \mathrm{Gpa}$ \\
\hline \multicolumn{2}{|c|}{ Ultimate elongation strain } & 0.025 \\
\hline \multicolumn{2}{|c|}{ compressive strengths } & $80 \mathrm{Mpa}$ \\
\hline \multicolumn{2}{|c|}{ Poisson's ratio } & $=0.35$ \\
\hline & tensile strengths & $=50 \mathrm{Mpa}$ \\
\cline { 2 - 3 } & Nominal thickness & $=0.3 \mathrm{~mm}$ \\
\hline
\end{tabular}

Table 4: Mechanical Properties of Epoxy

\begin{tabular}{|c|c|c|}
\hline Element Type & Material Properties & \\
\hline \multirow{3}{*}{ Solid 186 } & Linear isotropic & \\
\cline { 2 - 3 } & & $200000 \mathrm{Mpa}$ \\
\cline { 2 - 3 } & & 0.3 \\
\hline
\end{tabular}

Table 5: Material Properties Used For FE of Steel Plates

\subsection{Specimens Geometry and Specification}

In this study, specimen (columns) with dimensions and $150 \times 300 \times 500 \mathrm{~mm}$ was studied. The concrete cover and the corner's radius of $40 \mathrm{~mm}$ (see Figure 4). For specimen, four $12 \mathrm{~mm}$ steel bars were used as longitudinal reinforcement, and six $8 \mathrm{~mm}$ stirrups were used as the transverse reinforcements. Every specimen was fully wrapped with one, three, or five unidirectional FRP layers in transverse direction. The specimen identification labels are presented in Table 6. The primary letter in the mark represents rectangular cross segment. The next character represents the number of FRP layers used to externally confine the specimens.

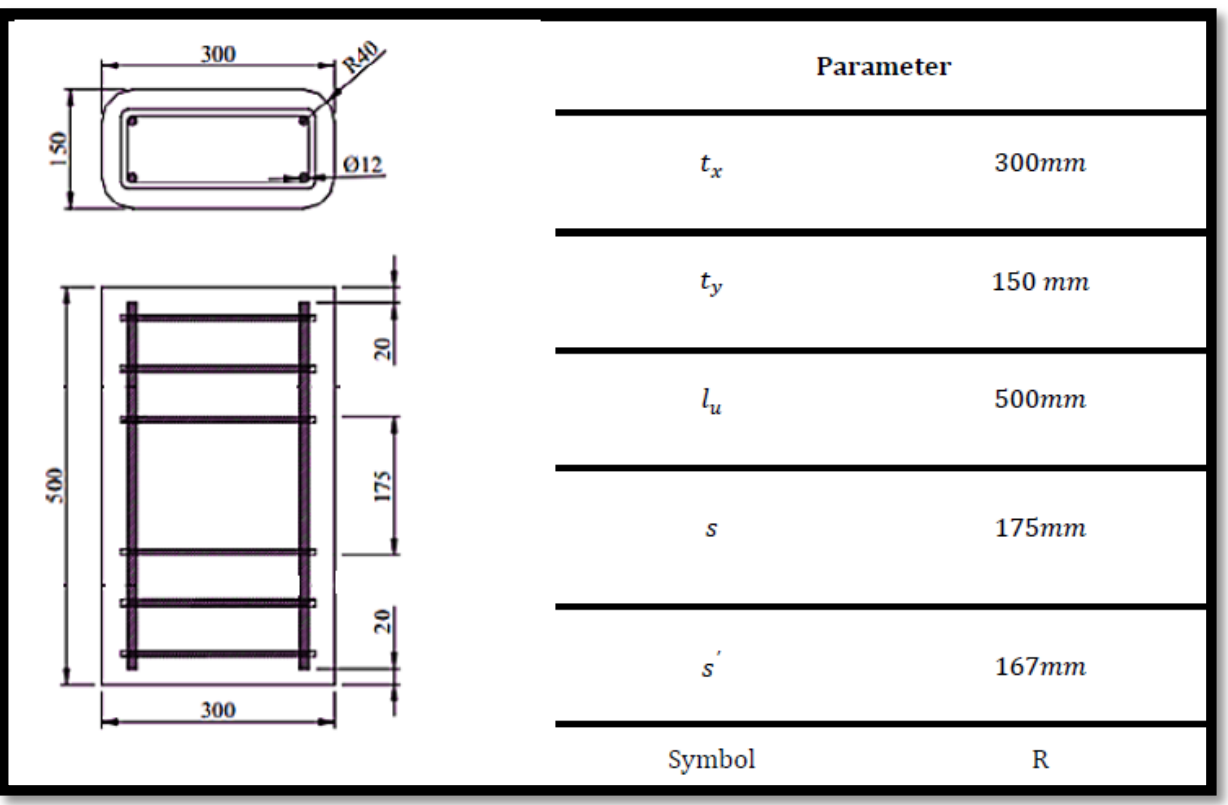

Figure 4: FRP Wrap Rectangular Layout and Column's Cross-Section 


\begin{tabular}{|c|l|c|}
\hline Symbol of Model & \multicolumn{1}{|c|}{ Data } & Number of Layers \\
\hline NS-R-2-175-0-40 & Experimental & 0 \\
\hline R-1 & Model & 1 \\
\hline R-3 & Experimental/Model & 3 \\
\hline R-5 & Model & 5 \\
\hline
\end{tabular}

Table 6: Specimens Specifications

\subsection{Boundary Conditions, Loading and Solution}

Due to the symmetry condition of the specimens, just a quarter of the specimens were modelled and the relating limit conditions were applied to $y z$ and $z x$ planes (see Figure 5/a). To reenact the steel plates at the finishes of the models, two plates were displayed with the mechanical properties of steel, in those zones. Pivotal stacking was applied on top surface of the stacking plate utilizing a client characterized stacking augmentation. The pivotal burden was applied to the top hubs of the stacking plate and the base plate (base plate) was fixed from displacement in $\mathrm{x}, \mathrm{y}$, and $\mathrm{z}$ headings. (Figure $5 / \mathrm{b}$ ) shows the limited component model of the rectangular specimens containing symmetric conditions. Various union upgrade includes in ANSYS like programmed load venturing, line search, etc. Can be enacted to aid the arrangement with combining. In the current examination the programmed load venturing and the line search choices were used. The programmed load venturing choice permits ANSYS to decide the quantity of burden steps needed for an exact arrangement. Sub-steps are characterized to apply the stacking, steadily. Have been set time at end sub-step 5000 also can be activated time increment, the size of time step was 0.2 , the minimum of time step 0.2 and the maximum of time step 0.1.

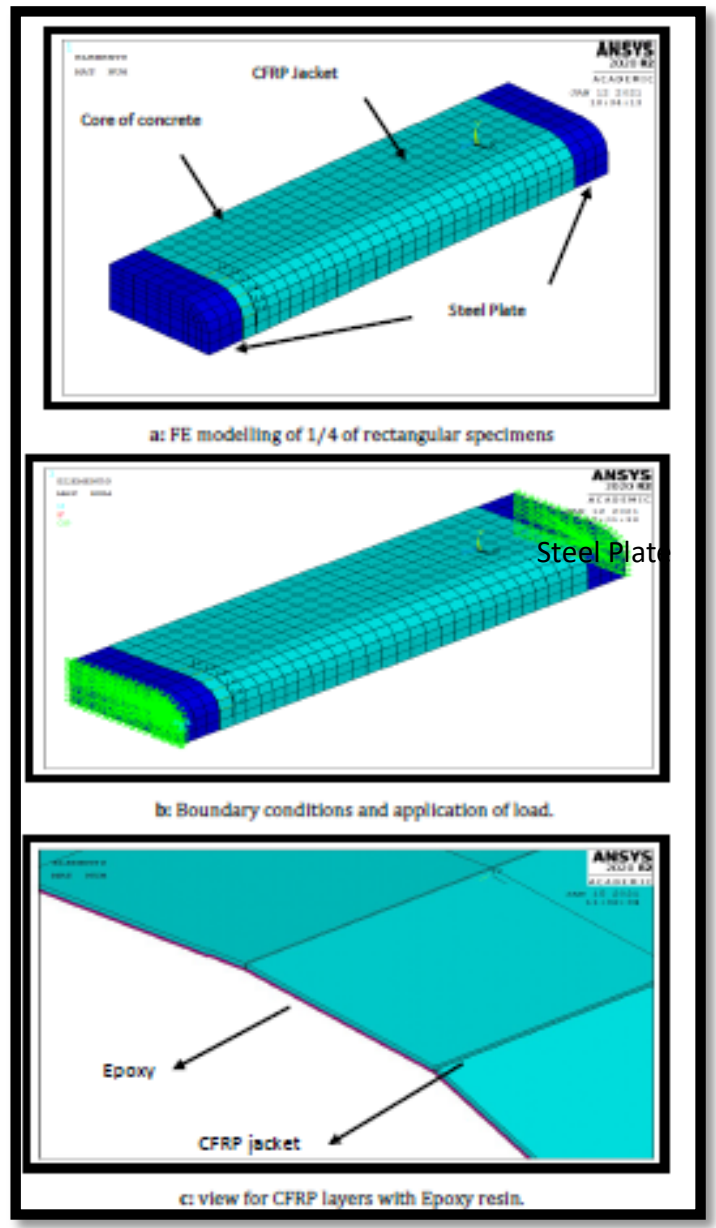

Figure 5: Modeling Steps of Studied Specimen 


\section{Analytical Method}

For prediction of ultimate strengths of CFRP jacketed specimens, the equations proposed by (ACI 440.2 -08). The compressive strength of confined concrete, $f_{\mathrm{cc}}^{\prime}$ as shown in Eq (4), is given by-

$f_{\mathrm{cc}}^{\prime}=k_{\mathrm{c}} f_{\mathrm{c}}^{\prime}$

Where $f_{\mathrm{c}}^{\prime}$ : the cylinder concrete compressive strength, $k_{\mathrm{c}}$ is a Factor depends on the biaxial state of stresses induced by the lateral confining pressures. This factor is given by:

$k_{\mathrm{c}}=\alpha_{1} \alpha_{2}$

Where $\alpha_{1}, \alpha_{2}$ are given by

$\alpha_{1}=1.25\left(1.8 \sqrt{1+7.94 \frac{F_{1}}{f_{\mathrm{c}}^{\prime}}}-1.6 \frac{F_{1}}{f_{\mathrm{c}}^{\prime}}-1\right)$

$\alpha_{2}=\left[1.4 \frac{f_{1}}{F_{1}}-0.6\left(\frac{f_{1}}{F_{1}}\right)^{2}-0.8\right] \sqrt{\frac{F_{1}}{f_{c}^{\prime}}}+1$

$\alpha_{1}$ and $\alpha_{2}$ concrete strength enhancement , $F_{1}$ and $f_{1}$ are the maximum and minimum confining lateral stresses, respectively.

The lateral confining stresses induced by FRP jacket only in the $x$ - and y-directions, $f_{1, j x}$ and $f_{1, j y}$, are:-

$f_{1, j x}=\rho_{j x} 0.005 E_{\mathrm{p}}$

$f_{1, j y}=\rho_{j y} 0.005 E_{\mathrm{p}}$

Where: $E_{\mathrm{p}}$ is the elastic modulus of the FRP jacket.

The reinforcement ratios $\rho_{\mathrm{jx}}$ and $\rho_{\mathrm{j} y}$ are defined as:

$\rho_{j x}=2 \frac{t_{j}}{t_{y}}$

$\rho_{\mathrm{j} y}=2 \frac{t_{\mathrm{j}}}{t_{x}}$

$t_{\mathrm{j}}, t_{\mathrm{x}}, t_{y}$ are the nominal jacket thickness, overall column cross-section in $x$ and $y$ direction dimensions respectively.

The lateral confining stresses induced by the steel hoops only in the $\mathrm{x}$ - and $\mathrm{y}$-directions, $f_{1, \mathrm{~s} x}$ and $f_{1, \mathrm{~s} y}$, are

$f_{1, \mathrm{sx}}=\rho_{\mathrm{sx}} f_{\text {syh }}$

$f_{1, s y}=\rho_{\text {sy }} f_{\text {syh }}$

Where $f_{\text {syh }}$ is the yield stress of the steel hoops.

$\rho_{\mathrm{sx}}=\frac{A_{\mathrm{t}, x}}{s d_{y}}$

$\rho_{\mathrm{sy}}=\frac{A_{\mathrm{t}, y}}{s d_{x}}$

$d_{x}, d_{y}$ are the distances between the centerlines of the perimeter hoop in the $x$ - and $y$-directions, respectively. $A_{\mathrm{t}, x}, A_{\mathrm{t}, y}$ are areas of transverse steel reinforcement parallel to the $x$ - and $y$-axis, respectively and $\mathrm{s}$ is the spacing between sets of hoops. The lateral confining stress acting upon area $A_{\mathrm{cc}, \mathrm{j}}$ due to both confining materials is equal to

$f_{1}=f_{1, \mathrm{~s}}+f_{1, \mathrm{j}}$

\section{Numerical Simulation Results and Discussion}

\subsection{Validation of Numerical and Analytical Model (Comparison FE Results with Experimental Data and Theoretical Analyti-} cal)

Non-linear FE analysis of RC columns are strengthened with layers of CFRP under the static incremental loads. The stress and strain of the columns are measured. The validation of the FE analysis of the FRP-wrapped RC columns was checked with an experimental study reported by (Ilki et al, 2008).

Figure 6: shows a comparison between the stress-strain response of the control specimens obtained from the tests and that resulted from the FE analysis. In addition, the comparison of the finite element analysis (FEA) and the experimental results are presented in Table 7.

Table 8 and Table 9 were shown the comparison of the theoretical analytical and the experimental results are presented, which $f^{\prime}{ }_{c c}$ and $\varepsilon_{c c u}$ are the maximum compressive stress and strain of the confined columns, respectively. It can be seen that the FE analysis results are very close to the test results. In addition, theoretical analytical results are very close to the test results in rectangular specimens but far in circular samples, this means that the FE model is valid for predicting the behavior of specimens and can be used to conduct a parametric study. 


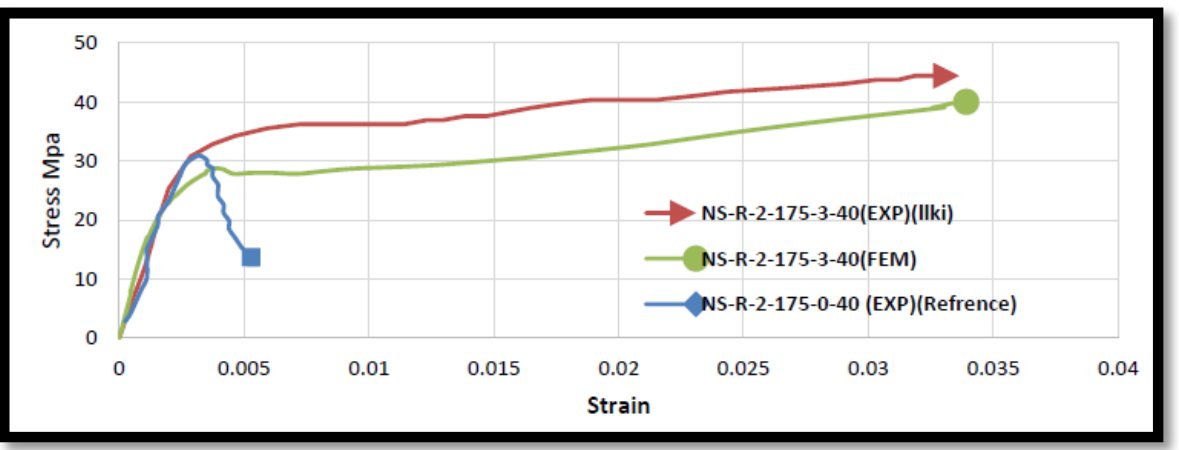

Figure 6: Comparison of the Stress-Strain of the Finite Element Modelling and Experimental Tests

\begin{tabular}{|c|c|c|c|}
\hline \multicolumn{2}{|c|}{ Specimens } & \multicolumn{2}{c|}{ R-3 } \\
\hline \multirow{2}{*}{$f^{\prime}{ }_{c c}$} & $E x p$ & $40.6 \mathrm{Mpa}$ & \multirow{2}{*}{ DIF $1.5 \%$} \\
\cline { 2 - 3 } & $F E$ & $40.0 \mathrm{Mpa}$ & \\
\cline { 2 - 3 }$\varepsilon_{c c u}$ & $E x p$ & $0.0336 \mathrm{~mm} / \mathrm{mm}$ & \multirow{2}{*}{ DIF $0.9 \%$} \\
\cline { 2 - 3 } & $F E$ & $0.0339 \mathrm{~mm} / \mathrm{mm}$ & \\
\hline
\end{tabular}

Table 7: Comparison of the Finite Element Modelling and Experimental Data

\begin{tabular}{|c|c|}
\hline Procedure & Calculations in SI metric units \\
\hline $\begin{array}{l}\text { Confining pressure due to the transverse steel rein- } \\
\text { forcement only. } \\
\qquad \begin{array}{cc}\rho_{\mathrm{sx}}=\frac{A_{\mathrm{t}, x}}{s d_{y}} & (14) \\
\rho_{\mathrm{sy}}=\frac{A_{\mathrm{t}, y}}{s d_{x}} & (15) \\
f_{1, \mathrm{sx}}=\rho_{\mathrm{sx}} f_{\text {syh }} & (12) \\
f_{1, s y}=\rho_{\mathrm{sy}} f_{\text {syh }} & (13)\end{array}\end{array}$ & $\begin{array}{c}A_{\mathrm{t}, x}=2 \times 50.25=100.5 \mathrm{~mm} 2 \\
A_{\mathrm{t}, y}=2 \times 50.25=100.5 \mathrm{~mm} 2 \\
d_{x}=300-(40 \times 2)+8=228 \mathrm{~mm} \\
d_{y}=150-(40 \times 2)+8=78 \mathrm{~mm} \\
s=175 \mathrm{~mm} \\
s^{\prime}=167 \mathrm{~mm} \\
\rho_{\mathrm{sx}}=\frac{100.5}{175 \times 78}=0.0074 \\
\rho_{\mathrm{sy}}=\frac{100.5}{175 \times 228}=0.0025 \\
f_{1, \mathrm{sx}}=0.0074 \times 476=3.52 \\
f_{1, s y}=0.0025 \times 476=1.19\end{array}$ \\
\hline 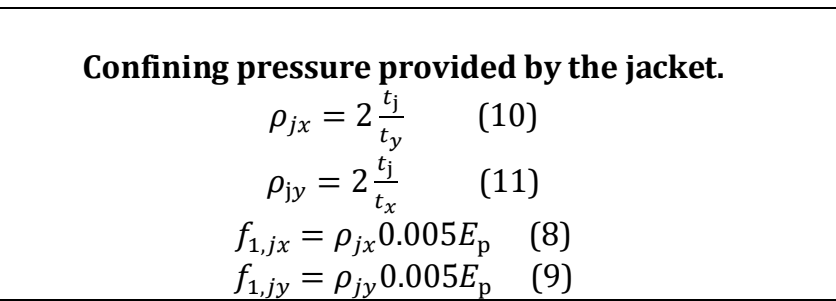 & $\begin{array}{c}\rho_{j x}=\frac{2 \times 3 \times 0.165}{150}=6.6 \times 10^{-3} \\
\rho_{\mathrm{jy}}=\frac{2 \times 3 \times 0.165}{300}=3.3 \times 10^{-3} \\
f_{1, j x}=6.6 \times 10^{-3} \times 0.005 \times 230000 \\
f_{1, j x}=7.59 \mathrm{Mpa} \\
f_{1, j y}=3.3 \times 10^{-3} \times 0.005 \times 3000 \\
f_{1, j y}=0.045 \mathrm{Mpa}\end{array}$ \\
\hline $\begin{array}{l}\text { Calculate the compressive strength of the concrete. } \\
\qquad f_{\mathrm{cc}, \mathrm{j}}^{\prime}=k_{\mathrm{c}} f_{\mathrm{c}}^{\prime} \\
k_{\mathrm{c}}=\alpha_{1} \alpha_{2} \\
\alpha_{1}=1.25\left(1.8 \sqrt{1+7.94 \frac{F_{1}}{f_{\mathrm{c}}^{\prime}}}-1.6 \frac{F_{1}}{f_{\mathrm{c}}^{\prime}}-1\right) \\
\alpha_{2}=\left[1.4 \frac{f_{1}}{F_{1}}-0.6\left(\frac{f_{1}}{F_{1}}\right)^{2}-0.8\right] \sqrt{\frac{F_{1}}{f_{\mathrm{c}}^{\prime}}}+1\end{array}$ & $\begin{array}{c}F_{1}=\max .\left(f_{1, j x}, f_{1, j y}\right)=7.59 \mathrm{Mpa} \\
f_{1}=\min .\left(f_{1, j x}, f_{1, j y}\right)=0.045 \mathrm{Mpa} \\
\alpha_{1}=1.25\left(1.8 \sqrt{1+7.94 \frac{7.59}{26.4}}-1.6 \frac{7.59}{26.4}-\right. \\
1)=2.25 \\
\alpha_{2}=\left[1.4 \frac{0.045}{7.59}-0.6\left(\frac{0.045}{7.59}\right)^{2}\right. \\
-0.8] \sqrt{\frac{7.59}{26.4}}+1=0.58 \\
k_{\mathrm{c}}=2.25 \times 0.58=1.31 \\
f_{\mathrm{ccj}}^{\prime}=1.31 \times 26.4=34.6 \mathrm{Mpa}\end{array}$ \\
\hline
\end{tabular}




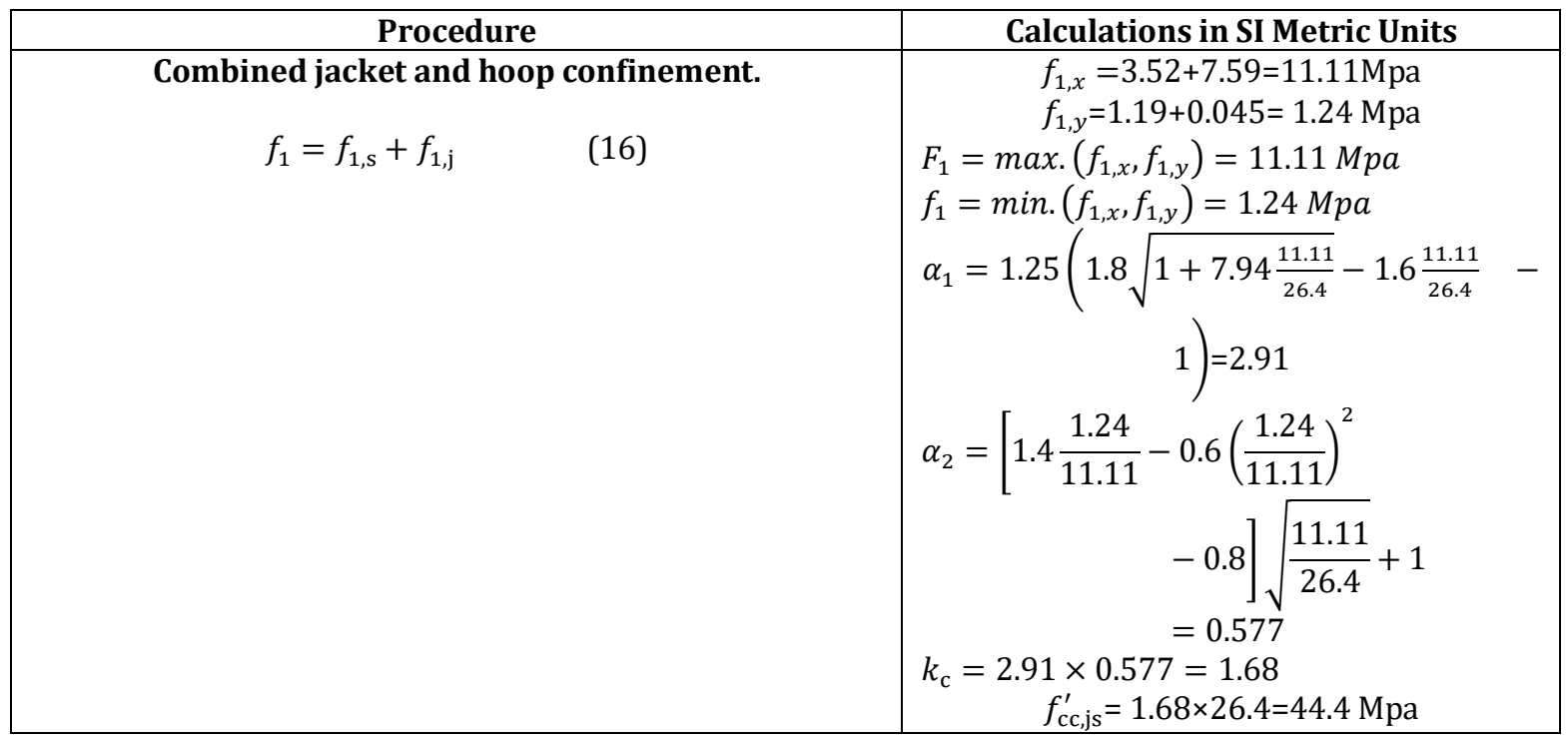

Table 8: Derivation of the Dependable Concentric Compression Load in the Column Using The ACI 318 Building Code, in SI Metric Units

\begin{tabular}{|c|c|c|c|}
\hline \multicolumn{2}{|c|}{ Specimens } & \multicolumn{2}{c|}{ R-3 } \\
\hline & & $40.6 \mathrm{Mpa}$ & \multirow{2}{*}{ DIF $9.4 \%$} \\
\cline { 2 - 3 } & Theoretical & $44.4 \mathrm{Mpa}$ & \\
\hline
\end{tabular}

Table 9: Comparison of the Theoretical Analytical and Experimental Data

\subsection{Parametric Study}

\subsubsection{Wrap Thickness Effect of CFRP}

The confinement effect on the ductility of the specimens, the ductility ratios of all of the specimens were calculated. Ductility can be surveyed the ductility ratio, $\mu$, which is defined by (Mohammad, Farshid \& Amir, 2010):

$\boldsymbol{\mu}=\frac{\text { Ultimate displacement }}{\text { Elastic displacement }}$

Figure 8: show the stress-strain response of FE analysis results for the RC columns with three different wrap layers (one, three, and five). It is observed significant enhancement in the compressive strength and ductility of the columns compared to unstrengthen columns. With increasing of the number of layers, lateral confining pressure is increased. According to this Figure, that mean of load

Carrying capacities was increased 77\%. Table 10 shows the ductility ratios of the specimens. The increasing proportions of ductility ratio (strengthened specimens to unstrengthened specimens) are provided in it. In addition, according to this Table the mean of ductility, ratios of rectangular specimens is 4.5 times of ductility ratios of unconfined specimens as it as mentioned, concrete is non-uniformly strengthened. Figure 9 shows distribution of the stress specimens, the shape of the cross section causes this phenomenon. In the specimens at any location of the cross section, different lateral pressure from FRP wrap is applied and therefore, the distribution of compressive stress becomes non-uniform

\begin{tabular}{|c|c|c|c|c|}
\hline \multirow[t]{2}{*}{$\boldsymbol{\mu}$} & \multirow{2}{*}{$\begin{array}{l}\text { Unstrengthened Ductility } \\
\text { Ratio (mm/mm) }\end{array}$} & \multirow{2}{*}{\multicolumn{2}{|c|}{$\begin{array}{c}\text { Strengthened } \\
\text { Ductility Ratio } \\
(\mathrm{mm} / \mathrm{mm}) \\
\end{array}$}} & \multirow[t]{2}{*}{ Proportion } \\
\hline & & & & \\
\hline \multirow[t]{3}{*}{$\mathrm{R}$} & \multirow[t]{3}{*}{1.54} & $\mathrm{R}-1$ & 4.35 & 2.82 \\
\hline & & $\mathrm{R}-3$ & 8.08 & 5.25 \\
\hline & & R-5 & 9.03 & 5.86 \\
\hline
\end{tabular}

Table 10: Ductility Ratios 


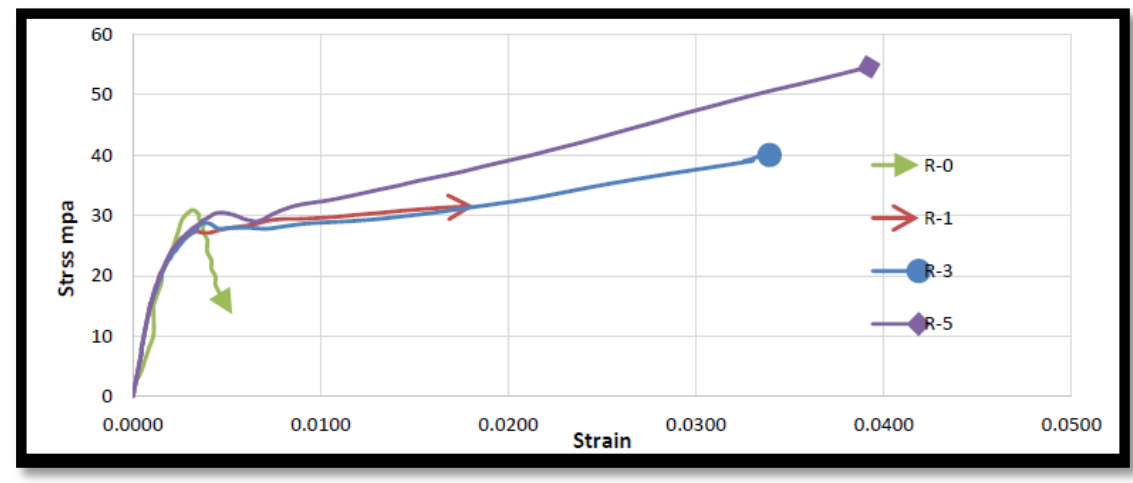

Figure 7: Stress-Strain Curves of RC Columns
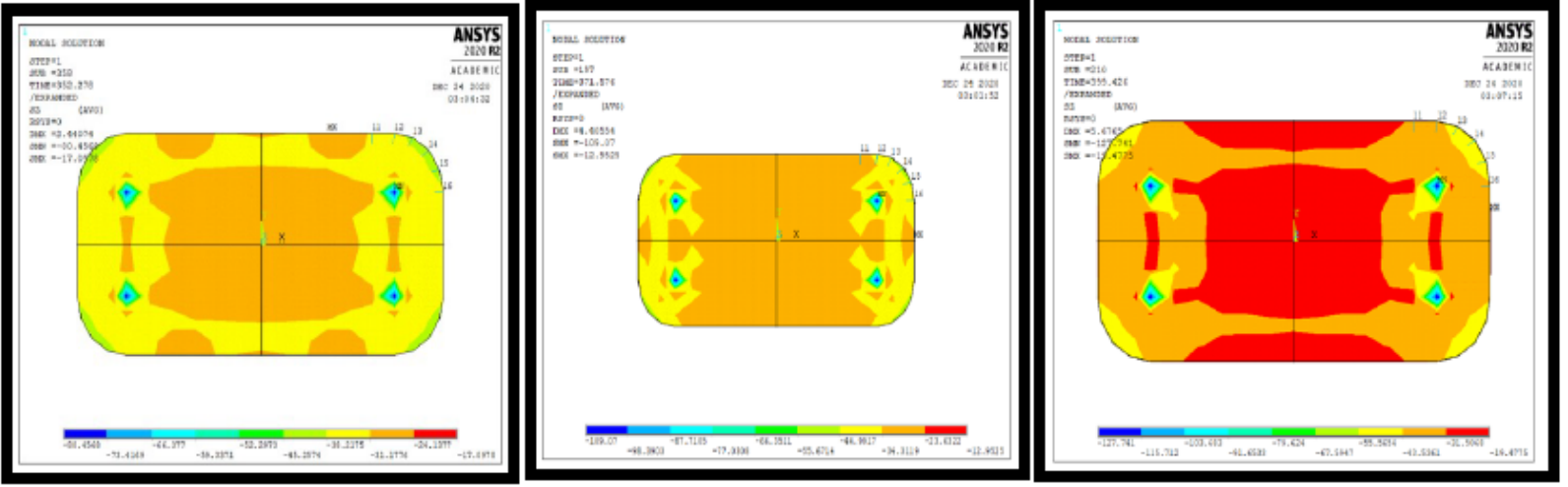

(a)- Section of RC column R-1

(b)- Section of RC column R-3

(c)- Section of RC column R-5

Figure 8: Contours of Axial Compressive Stress of Concrete Section of RC Column

\subsubsection{Fiber Orientation Effect on Specimen}

The effect of fiber orientation of FRP jacket on the stress-strain response of specimens R-3 is considered. The fire orientation $0^{\circ}, 15^{\circ}, 30^{\circ}$, and $45^{\circ}$ with respect to horizontal were considered. Figure 9: show the effect of the fiber orientation on the stress-strain response of specimens R-3. it was observed that the hoop orientation of fibres $\left(0^{\circ}\right)$ results in the largest gain in ultimate stress, while the fibre orientation of $\pm 15^{\circ}$ leads to the largest ultimate strain.

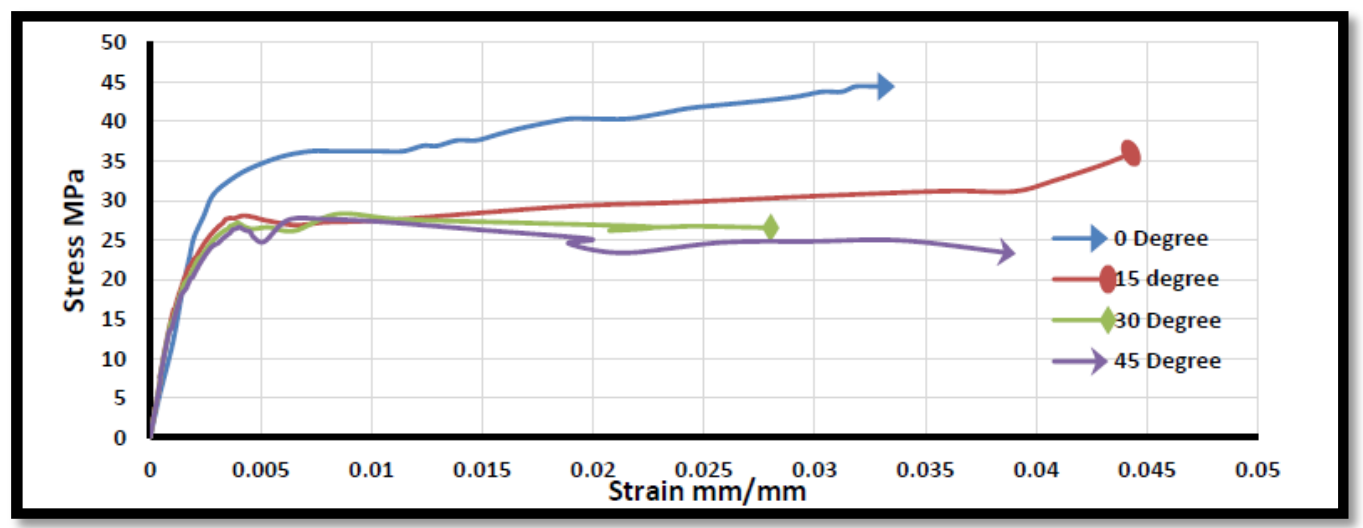

Figure 9: Effect of Fiber Orientation on Stress-Strain Response of Specimen R-3 


\section{Conclusion}

In the current study, FE simulation ANSYS and analytical model are used to evaluate the structural response of a CFRP-strengthened RC column. In addition, a parametric study consisting of three models (one, three, and five) CFRP layer is conducted. The following conclusions can be drawn from this model:

- 3-D finite element method results showed considerable increase in the axial compressive strength and ductility of the FRP-wrapped RC columns compared with the unstrengthened columns.

- when Increasing number of CFRP layers holding to the RC column soffit increases the stiffness of the column and increases its axial load capacity.

- $\quad \mathrm{RC}$ column strengthening by bonding a single layer of CFRP to the tension face of the column increases rectangular column strength by $4.2 \%$.

- $\quad \mathrm{RC}$ column strengthening by bonding two layers of CFRP to the tension face of the column increases rectangular column strength by $30 \%$ and RC column strengthening by bonding three layers of CFRP to the tension face of the column increases rectangular column strength by $77 \%$.

- The CFRP thickness has a significant effect on the strength and ductility of the columns so ductility ratio of rectangular are 4.5 times of ductility ratio of unconfined specimens.

- The gain in axial compressive strength was observed to be the highest in the columns wrapped with the hoop orientation; but the highest axial strain and ductility were observed in the columns wrapped with the fiber orientation of $\pm 15^{\circ}$ with respect to the horizon for rectangular column .

\section{Recommendations}

- In this study, the commercial Finite Element analysis software (ANSYS Academic 2020R2) was used in the analysis process. Comparative of studies Appling other available Finite Element software can be conducted to investigate which one can give more accurate results comparing with experimental investigations.

- In this study, the bond between concrete and CFRP fabric was Epoxy risen which simulate as layer (shell element). Although this simulation did not cause a significant error in the obtained results comparing with experimental investigations, the behavior of the concrete-CFRP bond and de-bonding issues can be concentrated analytically to get more accurate results especially regarding failure modes.

- In this study, The RC column external strengthening with CFRP was investigated. Strengthening with other available Fiber Reinforced Polymer (FRP) materials as Glass Fiber Reinforced Polymer (GFRP) can be concentrated to investigate the efficiency of the strengthening technique utilizing different materials with various properties.

\section{References}

i. ACI (2008), "ACI 440.2-08 guide for the design and construction of externally bonded FRP systems for strengthening concrete structures", ACI, Farmington Hills, MI.

ii. Hajsadeghi, M., Alaee, F. J., \& Shahmohammadi, A. (2011). "Investigation on behaviour of square/rectangular reinforced concrete columns retrofitted with FRP jacket". Journal of Civil Engineering and Management, 17(3), 400-408.

iii. Carrillo, J., Valencia-Mina, W., \& Bojórquez, E. (2020), "Compressive performance of square and low-strength concrete columns retrofitted with externally bonded CFRP". Materials Today Communications, 23, 100874.

iv. OLIVEIRA, D., \&

v. CARRAZEDO, R. (2019), "Numerical modeling of circular, square and rectangular concrete columns wrapped with FRP under concentric and eccentric load". Revista IBRACON de Estruturas e Materiais, 12(3), 518-550.

vi. Benredjem, A., Chikh, N., Mesbah, H. A., \& Benzaid, R. (2018), "Structural behaviour of square RC columns confined with CFRP wraps". In MATEC Web of Conferences (Vol. 149, p. 02095). EDP Sciences.

vii. ANSYS Mechanical APDL Manual Set. (2014). Release 14.5. Southpointe: ANSYS Inc.

viii. Abdulla, M. D., \& Khaduier, Z. A. (2018). "Nonlinear Finite Elements Analysis of Reinforced Concrete Columns Strengthened With Carbon Fiber Reinforced Polymer (CFRP)". Journal of University of Babylon for Engineering Sciences, 26(3), 75-97.

ix. Chansawat, K., Potisuk, T., Miller, T. H., Yim, S. C., \& Kachlakev, D. I. (2009), "FE models of GFRP and CFRP strengthening of reinforced concrete beams", Advances in Civil Engineering, 2009.

x. Isenberg, J. (1993), "Finite element analysis of reinforced concrete structures II", ASCE.

xi. Mohammad, H. (2015), "Non-linear Finite Element Analysis of Reinforced", gaza, Palestine, Palestine: The Islamic University of gaza. Kohnke, P. (2013). "ANSYS mechanical APDL theory reference". Canonsburg, PA, USA: 
ANSYS Inc. Wolanski, A. J. (2004), "Flexural behaviour of reinforced and prestressed concrete beams using finite element analysis", PhD thesis, Marquette University.

xii. Basappa, U., \& Rajagopal, A (2013), "Modeling of CFRP strengthened RCC beam using the nonlinear finite element method. Journal of Structural Engineering", 40(2), 169-184.

xiii. ANSYS, ANSYS User's Manual Revision 5.5, ANSYS, Inc., Canonsburg, Pennsylvania, 1998.

xiv. Wang, Y. C., \& Hsu, K. (2008), "Design of FRP-wrapped reinforced concrete columns for enhancing axial load carrying capacity", Composite structures, 82(1), 132-139.

xv. Ilki, A., Peker, O., Karamuk, E., Demir, C., \& Kumbasar, N. (2006), "Axial behavior of RC columns retrofitted with FRP composites", In Advances in earthquake engineering for urban risk reduction (pp. 301-316). Springer, Dordrecht 